\title{
Effect of fiber orientation and specimen thickness on the tensile response of strain hardening UHPFRC mixes with reduced Embodied Energy
}

\author{
Amir Hajiesmaeili ${ }^{1}$ and Emmanuel Denarié ${ }^{1}$ \\ ${ }^{1}$ Division of Maintenance and Safety of Structures (MCS-IIC-ENAC), Ecole \\ Polytechnique Fédérale de Lausanne (EPFL), GC B3-445, Station 18, CH-1015 \\ Lausanne, Switzerland; fax. +41 2169358 85, email: amir.hajiesmaeili@epfl.ch .
}

\begin{abstract}
Ultra-High Performance Fiber Reinforced Concretes (UHPFRC) have demonstrated their potential to contain the explosion of maintenance costs (Economy and Environment) for civil engineering structures, due to their extremely low permeability associated with the outstanding mechanical properties. Substitution of EmbodiedEnergy (EE)-costly components of UHPFRC such as clinker and steel fibers, is the next step towards sustainability, to make it even more efficient and more environmentfriendly. In this study, a strain hardening UHPFRC mix with two main modifications has been developed in which (1) $75 \%$ of steel fibers have been replaced by ultra-high molecular weight polyethylene (UHMWPE, henceforth referred to as PE) fibers and (2) $50 \%$ volume of cement type CEM I have been replaced with limestone filler.

The effect of the fiber orientation and the specimen thickness on the mechanical properties of such mixes have been investigated. The mechanical properties have been investigated using direct tensile test, and 4-point bending test. Finally, the dramatic effect of fiber orientation on the ultimate strength and deformability has been demonstrated. Moreover, the results confirm that the specimen thickness affects the deformation capacity of the specimens. Finally, improvements in terms of reduction of EE of the proposed mixes, are highlighted.
\end{abstract}

Keywords: UHPFRC, Mechanical response, Strain Hardening, UHMW-PE fibers, Embodied Energy

\section{INTRODUCTION}

Current UHPFRC, for structural applications in new constructions and rehabilitation of existing structures, are almost exclusively based on steel fibers. A few notable investigations have been conducted on using UHPFRC with synthetic fibers for structural applications. The synthetic fibers are mostly used in UHPFRC for facade elements with complex shapes (Chen and Chanvillard, 2012). Considering the fact that more than 50\% of the EE and GWP impact of the UHPFRC is from the steel fibers contribution (Stengel and Schieß1, 2008), replacing the steel fibers with synthetic fibers has a considerable effect on reducing the EE of this material. 
Beginning as early as the 1990s, interest in creating a synthetic fiber reinforced concrete material with tensile ductility has been gaining ground. The first attempts to employ synthetic fibers in concrete in order to achieve a strain hardening composite were performed by $\mathrm{Li}$ (1993). He used micromechanics theory with the aim of obtaining evenly distributed multiple microcracks under tension, the widths of which were smaller than durability related limits. ECC (Engineered Cementitious Composite) was the result of his research; a material with PE or PVA fibers, around 4.5 MPa tensile strength and 5\% strain hardening capacity.

Kunieda et al. (2007) and Kamal (2008) tried to develop a material with the advantages of both UHPFRC and Strain Hardening Cementitious Composites (SHCC), with high performance PE fibers. They achieved UHP-SHCC material with a dense matrix, significant strain hardening capacity (close to $1 \%$ ), relatively high compressive strength (83 MPa) compared to normal SHCC (20.2 MPa), and tensile strength of 4.5 MPa.

This trend was continued by Ranade et al. (2013) using PE fibers in High-Strength, High-Ductility Concrete (HSHDC). They achieved an ultimate tensile strength of 14 $\mathrm{MPa}$ at 3.5\% deformation and compressive strength of $160 \mathrm{MPa}$.

However, the tensile specimens used in all these studies were small, narrow and thin (12 $\mathrm{mm}$ thick and $30 \mathrm{~mm}$ wide in the central part), which, due to the better fiber orientation and the de-airing performance of the mix, is likely to overestimate the tensile performance compared to application with thicker (30 to $50 \mathrm{~mm}$ ) and wider layers, which are common in rehabilitation of structural members or new constructions. In this paper, first of all, an improved cementitious material reinforced with PE and steel fibers has been developed. In order to make the new material more environmentally friendly when compared to the normal strain hardening UHPFRC, half of the cement has been replaced by limestone filler and $75 \%$ of steel fibers have been replaced by PE fibers. In the second step, the effect of fiber orientation and the specimen thickness of such mixes on mechanical properties have been investigated using direct tensile and 4-point bending tests.

\section{MATERIAL DESIGN}

Packing density is the key concept for obtaining Ultra high-performance cementitious composites. Maximizing the packing density with the help of different grain classes reduces the voids in the matrix, which had to be filled with water at fresh state. Therefore, more excess water to lubricate the solid particles and enhance the workability is made available. Hence, increasing the packing density can improve the overall workability-strength performance of the cementitious material by opening up the possibility of using low W/B ratios with a wide range of fibrous mixes.

The Compressible Packing Model (CPM) (De Larrard, 1999) basically considers the energy required to compact a mix of several monosized particle classes. It also considers the loosening effect on large particles by interstitial small ones, and the wall effect within assemblies of small particles near a large one like a fiber or a container wall. Sedran (1999) generalized the CPM to consider the interaction of grain classes with arbitrary Particle Size Distributions (PSD).

In this study, the generalized CPM model was implemented in the MATLAB software. Five different powders including cement, two types of limestone filler, silica fume and 
sand were used in the mixes. More than 20 mix designs were modeled. Finally, 40 x 40 $\mathrm{x} 160 \mathrm{~mm}$ prism specimens, of the five mixes with highest packing densities were cast in the laboratory and the final mix was chosen based on the 3-point bending performances. The mixture proportions of a normal strain hardening UHPFRC and the final mix are given in table 1 and table 2 respectively. Moreover, figure 1 shows the particle size distribution of the solid materials used in the formulation of the matrix together with that of the final mix. The packing density of the final mix is 0.78 .

Table 1. A normal SH-UHPFRC mixture proportion (Denarié et al., 2011)

\begin{tabular}{ccccccc}
\hline Component & Cement & Silica fume & Fine Sand & Water & HRWRA & Steel fiber \\
\hline$\left[\mathrm{kg} / \mathrm{m}^{3}\right]$ & 1200 & 150 & 600 & 200 & 45 & 353 \\
\hline
\end{tabular}

Table 2. The mixture proportions of the final mix (PE18)

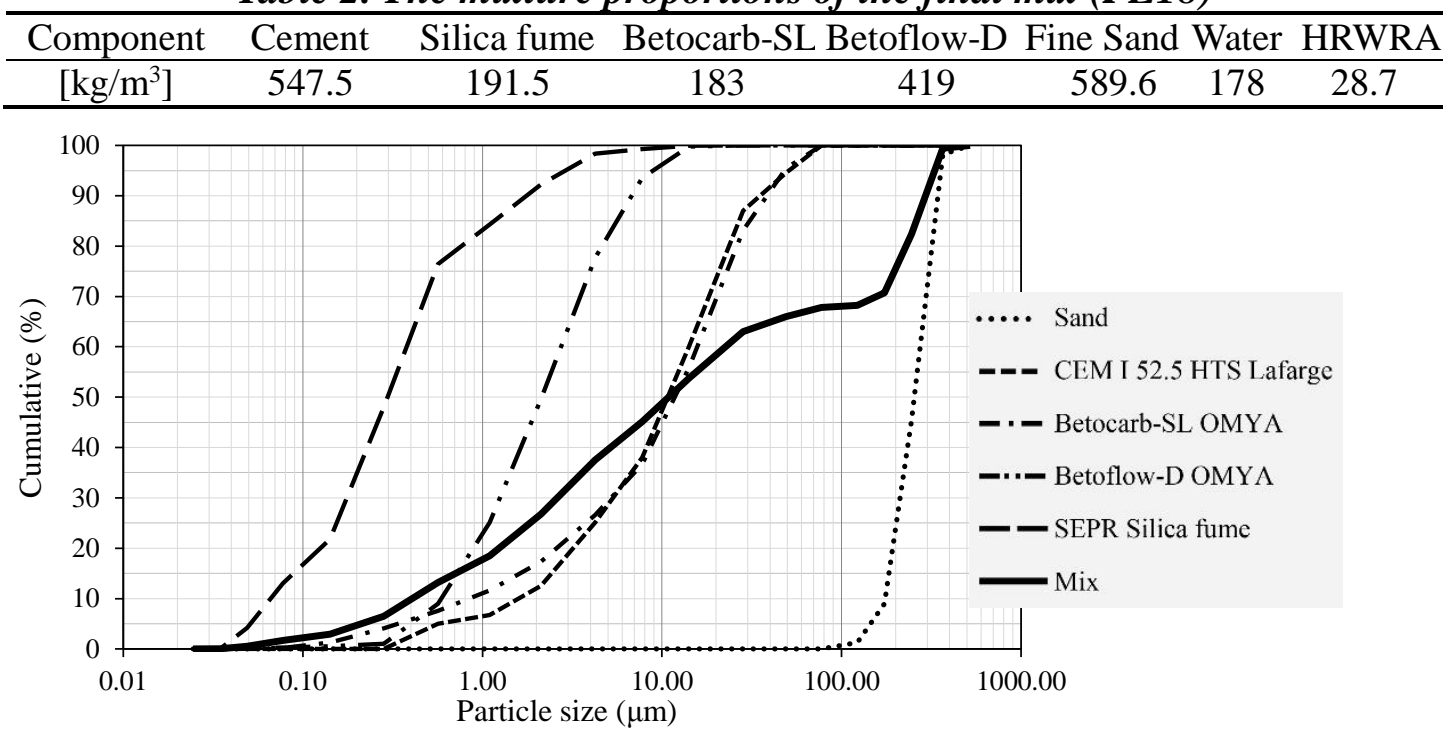

Figure 1. Particle size distribution of the components and the final mix

The fibrous mix includes 1\% volume steel fiber and 2\% volume PE fiber. The physical/mechanical properties and geometry of these fibers are given in table 3 .

Table 3. Geometry and mechanical/physical properties of the fibers

\begin{tabular}{ccccccc}
\hline Type & $\begin{array}{c}\text { Volume } \\
\text { fraction } \\
{[\%]}\end{array}$ & $\begin{array}{c}\text { Diameter } \\
{[\mu \mathrm{m}]}\end{array}$ & $\begin{array}{c}\text { Length } \\
{[\mathrm{mm}]}\end{array}$ & $\begin{array}{c}\text { Elastic } \\
\text { Modulus } \\
{[\mathrm{GPa}]}\end{array}$ & $\begin{array}{c}\text { Tensile } \\
\text { strength } \\
{[\mathrm{MPa}]}\end{array}$ & $\begin{array}{c}\text { Specific } \\
\text { gravity }\end{array}$ \\
\hline Steel & 1 & 200 & 10 & 200 & 2000 & 7.85 \\
UHMPE & 2 & 16 & 10 & 130 & 3000 & 0.97 \\
\hline
\end{tabular}

Table 4 shows the 3-point bending performance and compressive strength of the final mix. After casting, the specimens were sealed with a plastic cover for 4 days at room temperature of $20 \pm 5^{\circ} \mathrm{C}$. This was followed by an elevated thermal curing for 3 days at $85^{\circ} \mathrm{C}$ under $95 \% \mathrm{RH}$. The specimens were then kept unsealed at room temperature of $20 \pm 5^{\circ} \mathrm{C}$ before testing at 14 days.

Table 4. The average MOR and compressive strength of $40 \times 40 \times 160$ specimens

\begin{tabular}{cc}
\hline MOR $[\mathrm{MPa}]$ & Compressive strength $[\mathrm{MPa}]$ \\
\hline 30.6 & 170.4 \\
\hline
\end{tabular}




\section{EXPERIMENTAL PROGRAM}

\subsection{Specimen preparation}

The experimental program was designed in a way to investigate the effect of fiber orientation as well as specimen thickness on the mechanical properties.

- Inspired from Wuest et al. (2009) and Ferrara et al. (2011), in order to study the fiber orientation effect, two square plates of $580 \times 580 \times 30 \mathrm{~mm}$ were cast with the material poured from one end to the other, without joints. Figure 2a illustrates the casting procedure. Afterward, three dumbbell specimens $(560 \mathrm{~mm}$ long) for the direct tensile test and two $500 \times 100 \mathrm{~mm}$ specimens for the 4-point bending test were cut from each plate with a waterjet machine; one set parallel to the direction of casting and the other set perpendicular to the direction of the casting. Figure $2 \mathrm{~b}$ and $2 \mathrm{c}$ show the position of the specimens that were cut from the $580 \times 580 \mathrm{~mm}$ plates. In order to avoid surfacing, the top surfaces of the two plates were covered immediately after pouring with a wood panel to which Controlled Permeability Formliner (CPF) - Zemdrain ${ }^{\circledR}$ sheets were attached, to guarantee a flat and uniform upper surface after setting.

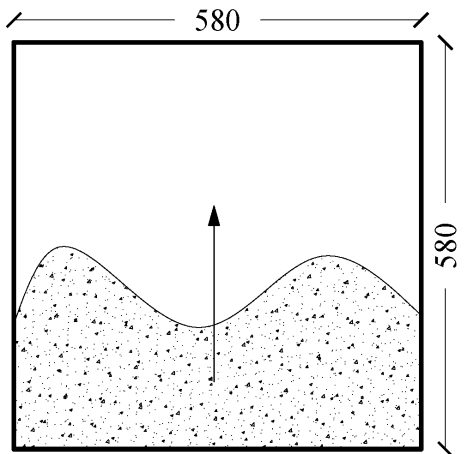

(a)

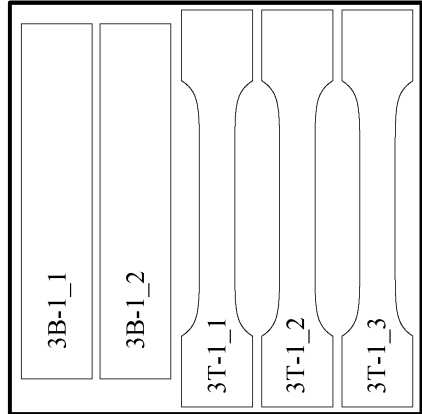

(b)

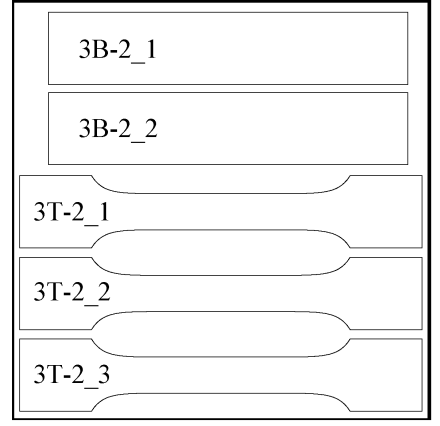

(c)

Figure 2. the specimens to study the fiber orientation effect; (a) the casting direction, (b) the specimens parallel to the casting direction and (c) the specimens perpendicular to the casting direction

- With a view to investigating the effect of specimen thickness on the mechanical properties, three specimens of $500 \times 200 \times 50 \mathrm{~mm}$ and three specimens of $500 \times 200 \times$ $10 \mathrm{~mm}$ were cast. From each of them, one dumbbell specimen (490 mm long) and one $490 \times 95 \mathrm{~mm}$ specimen were cut with waterjet for the direct tensile and 4-point bending tests respectively.

To limit as far as possible the stress concentrations, Neuber's (1969) solution was adapted to the geometry of the dumbbell specimens. There are three types of tensile specimens with geometry and gauge length as shown in figure 3. Type I is $560 \mathrm{~mm}$ long, $30 \mathrm{~mm}$ thick and $50 \mathrm{~mm}$ wide. It has one LVDT at each side (4 in total) in order to check the eccentricities in both directions to avoid bending effects while loading. The gauge lengths of the LVDT are $300 \mathrm{~mm}$ and $200 \mathrm{~mm}$ for this specimen. Type II is $490 \mathrm{~mm}$ long, $50 \mathrm{~mm}$ thick and $50 \mathrm{~mm}$ wide, with the similar installation of LVDTs as the specimen type I, and with the gauge lengths of $345 \mathrm{~mm}$ and $220 \mathrm{~mm}$ in opposite directions. Type III is $490 \mathrm{~mm}$ long, $10 \mathrm{~mm}$ thick and $50 \mathrm{~mm}$ wide and has two LVDTs in one direction with a gauge length of $220 \mathrm{~mm}$. 
Thermal curing was applied to all specimens. The specimens were sealed after casting with plastic for 4 days at room temperature of $20 \pm 5^{\circ} \mathrm{C}$. This was followed by elevated thermal curing for 3 days at $85^{\circ} \mathrm{C}$ under $95 \% \mathrm{RH}$. The specimens were then kept unsealed at room temperature of $20 \pm 5^{\circ} \mathrm{C}$ before testing at 14 days.

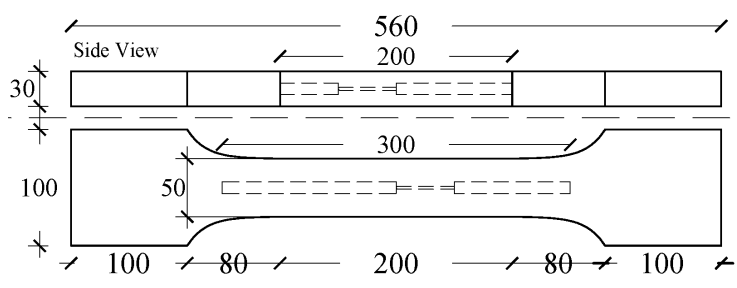

(a)

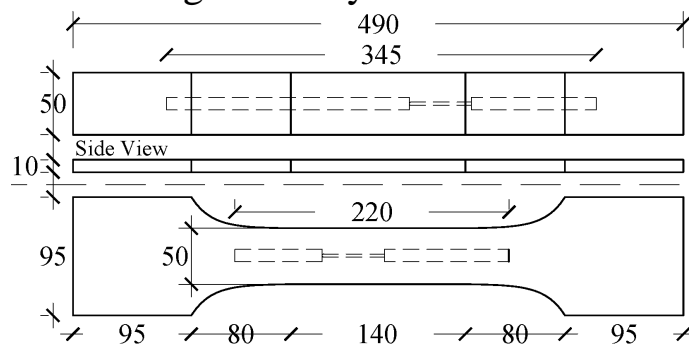

(b)

Figure 3. The dumbbell specimen geometry for the tensile testing (a) specimen type I and (b) specimens type II and III (all dimensions in $\mathrm{mm}$ )

\subsection{Experimental setup}

Direct tensile tests were performed under quasi-static uniaxial loading under displacement control with a stroke rate of $0.4 \mathrm{~mm} / \mathrm{min}$. The dumbbell specimens were gripped on their faces in a fixed-fixed type of end constraints using hydraulic clamping system.

The 4-point bending tests on the plates were done following Denarié (2015). The tests were performed under displacement control at a stroke rate of $0.5 \mathrm{~mm} / \mathrm{min}$. The support span of flexural loading was $420 \mathrm{~mm}$ and the loading span was $140 \mathrm{~mm}$. The force was measured by the load cell of the testing machine, and the mid-span deflection was recorded using two LVDTs placed at mid-span, attached to a measuring frame fixed to the middle axis of the specimen, on the support points, during the test.

\section{RESULTS AND DISCUSSION}

\subsection{Fiber orientation effect}

The results of the direct tensile tests on dumbbell specimens that were cut parallel and perpendicular to the direction of casting are presented in figure 4 . The results are presented in the stress-displacement format in order to be able to show the postcracking behavior. The gauge length for this set of data is $300 \mathrm{~mm}$.

As the results show, the fiber orientation has a strong effect on the mechanical properties of the material. The ultimate strength of the specimens that were cut perpendicular to the casting direction is reduced by around $30 \%$ and the deformation capacity is decreased by around $50 \%$ when compared to that of the specimens cut parallel to the casting direction. Increasing the fibers inclination angle with respect to the direction of principal stresses, reduces their overall performance in the composite and thus decreases its ultimate strength as well as its deformability; for stiff fibers and likewise also for flexible ones.

The 4-point bending behavior of the two types of specimens is presented in figure 5 . According to this set of data, the results of the 4-point bending tests follow the same trend as that of the direct tensile tests on ultimate strength and deformability, and soundly confirm the important effect of fiber orientation on the mechanical properties of these materials. 


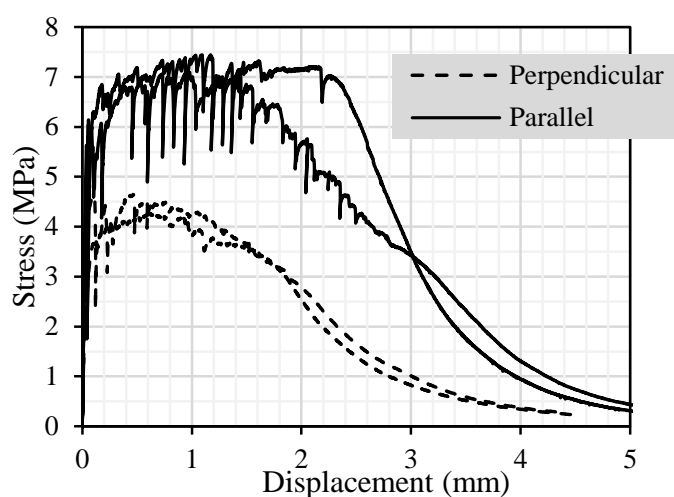

Figure 4. direct tensile test results of dumbbell specimens cut parallel and perpendicular to the casting direction (gauge length is $300 \mathrm{~mm}$ )

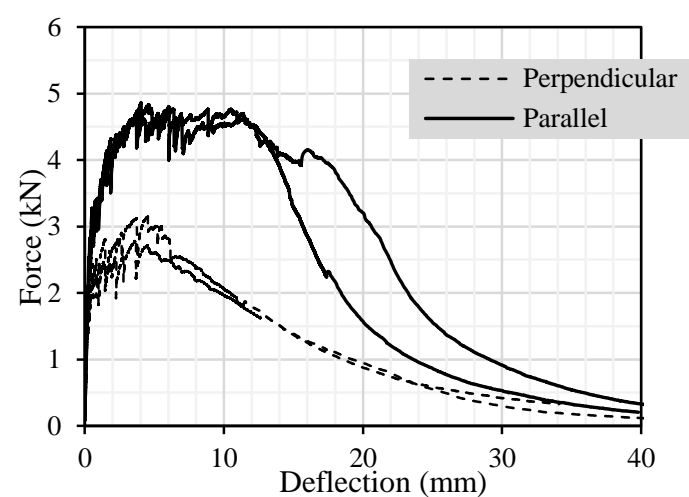

Figure 5. 4-point bending behavior of $500 \times 100 x 30$ plates that were cut perpendicular and parallel to the casting direction

\subsection{Specimen thickness effect}

The 4-point bending responses of the $10 \mathrm{~mm}$ and $50 \mathrm{~mm}$ thick specimens are shown in figure 6. In this figure, the force is scaled so that it is comparable with the results of the $30 \mathrm{~mm}$ thick specimens, by multiplying the actual force by (30/specimen thickness) ${ }^{2}$, as the bending strength is expected to vary with the square of the specimen height.

The deformability of the specimens is increased by decreasing the thickness whereas the ultimate load is not affected. Additionally, the results of the direct tensile tests, which are presented in figure 7 , fairly verify this trend. The position of the extent of the hardening zone is shown with vertical lines for each specimen thickness in this figure.

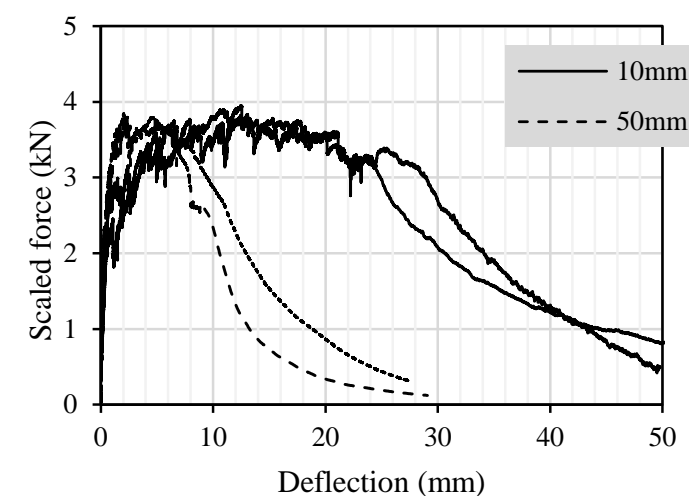

Figure 6. 4-point bending behavior of $10 \mathrm{~mm}$ and $50 \mathrm{~mm}$ thick plates

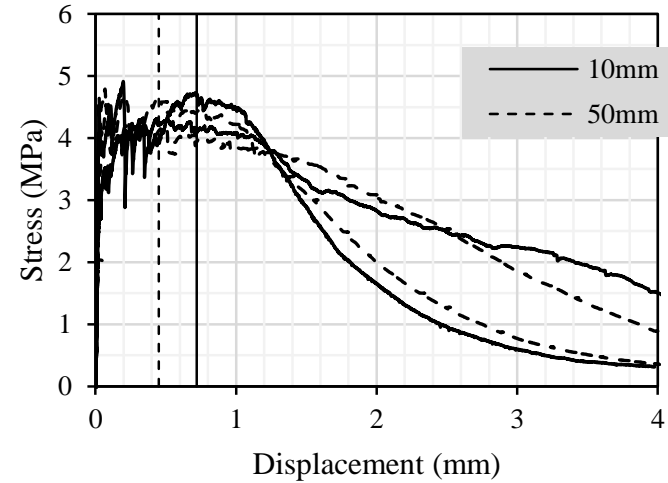

Figure 7. direct tensile test results of $10 \mathrm{~mm}$ and $50 \mathrm{~mm}$ thick dumbbell specimens (gauge length is $220 \mathrm{~mm}$ )

Regarding the ultimate strength, decreasing the specimen thickness reduces the distance that an air bubble has to travel in order to leave the fresh material. Thus, the thinner specimens should generally show a higher mechanical performance due to their less void content. However, in this case, it seems that the dense network of the PE fibers entraps the air bubbles and slows down the de-airing of the material at the 
fresh state. In addition, no obvious difference can be seen between the bottom surface of the specimens with $10 \mathrm{~mm}$ and $50 \mathrm{~mm}$ thick. Accordingly, assuming that decreasing the thickness does not improve the de-airing behavior of such a material, it can be concluded that the specimen thickness does not affect the ultimate strength of such mixes to a large extent.

\section{CONCLUSIONS}

- A SH-UHPFRC mix with reduced Embodied Energy has been developed in which, $50 \%$ of cement is replaced by limestone filler and $75 \%$ of steel fiber is replaced by PE fibers.

- After Table 5, 60\% reduction in the EE in the new mix compared to a normal strain hardening UHPFRC as well as reduction of $300 \mathrm{~kg} / \mathrm{m}^{3}$ in the dead weight of the material were achieved.

Table 5. Comparison of EE between a normal SH-UHPFRC and the new mix

\begin{tabular}{lccc}
\hline & & SH-UHPFRC & New mix \\
\hline Total EE & {$\left[\mathrm{MJ} / \mathrm{m}^{3}\right]$} & $28^{\prime} 830$ & $11^{\prime} 390$ \\
Specific weight & {$\left[\mathrm{kg} / \mathrm{m}^{3}\right]$} & $2^{\prime} 550$ & $2^{\prime} 250$ \\
\hline
\end{tabular}

- Fiber orientation and specimen thickness have a considerable effect on the mechanical properties. The specimen thickness mostly affects the deformability of the specimen. Likewise, the fiber orientation affects the ultimate strength as well as deformation capacity.

- Currently, most of the research results in the field of PE fiber reinforced cementitious material are based on the JSCE (2008) tensile specimen preparation methodology. This methodology with a thin and narrow $(12 \mathrm{~mm}$ thick and $30 \mathrm{~mm}$ wide) specimen overestimates the tensile performance of the material, with respect to its potential performance in structural applications wherein less favorable fiber orientation is encountered.

\section{ACKNOWLEDGMENTS}

This project is financially supported by the Swiss National Science Foundation (grant 407040_154063 / 1) through the National Research Program "Energy Turnaround" (NRP 70). The authors would like to acknowledge Dyneema, Omya, LafargeHolcim, and Sika for donating the PE fiber, limestone filler, cement and superplasticizer respectively.

\section{REFERENCES}

CHEN, J. \& CHANVILLARD, G. UHPC composites based on glass fibers with high fluidity, ductility, and durability. Ultra-High Performance Concrete and Nanotechnology in Construction. Proceedings of Hipermat, March 7-9 2012 Kassel. 265-272. 
DE LARRARD, F. 1999. Concrete mixture proportioning: a scientific approach, CRC Press.

DENARIÉ, E. Essais de caractérisation-réponse en traction. Acte de la 2ème journée d" étude du 22 octobre 2015: Béton fibré ultra-performant-Concevoir, dimensionner, construire, 2015. Haute école d" ingénierie et $\mathrm{d}$ " architecture Fribourg und Berner Fachhochschule, 25-36.

DENARIÉ, E., KAZEMI KAMYAB, M., BRÜHWILER, E., HADDAD, B. G. \& NENDAZ, S. 2011. Béton fibré ultra performant pour la maintenance, un nouvel élan.

FERRARA, L., OZYURT, N. \& DI PRISCO, M. 2011. High mechanical performance of fibre reinforced cementitious composites: the role of "casting-flow induced" fibre orientation. Materials and Structures, 44, 109-128.

JSCE 2008. Recommendations for Design and Construction of High Performance Fiber Reinforced Cement Composites with Multiple Fine Cracks. Tokyo, Japan: Japan Society of Civil Engineers.

KAMAL, A. 2008. Material development of UHP-SHCC for repair applications and its evaluation. $\mathrm{PhD}$, Nagoya University.

KUNIEDA, M., DENARIÉ, E., BRÜHWILER, E. \& NAKAMURA, H. Challenges for strain hardening cementitious composites-deformability versus matrix density. HPFRCC5, 2007.

LI, V. C. 1993. From micromechanics to structural engineering - the design of cementitious composites for civil engineering applications. Doboku Gakkai Rombun-Hokokushu/Proceedings of the Japan Society of Civil Engineers, 1-12.

NEUBER, H. 1969. Der zugbeanspruchte Flachstab mit optimalem Querschnittsübergang. Forschung im Ingenieurwesen A, 35, 29-30.

RANADE, R., LI, V. C., STULTS, M. D., HEARD, W. F. \& RUSHING, T. S. 2013. Composite properties of high-strength, high-ductility concrete. ACI Materials Journal, 110, 413-422.

SEDRAN, T. 1999. Rhéologie et rhéométrie des bétons. Application aux bétons autonivelants. doctorat, Ecole Nationale des Ponts et Chaussées.

STENGEL, T. \& SCHIEßL, P. Sustainable construction with UHPC-from life cycle inventory data collection to environmental impact assessment. Proceedings of the 2nd international symposium on ultra high performance concrete. Kassel University Press, Kassel, 2008. 461-468.

WUEST, J., DENARIÉ, E., BRÜHWILER, E., TAMARIT, L., KOCHER, M. \& GALLUCCI, E. 2009. Tomography Analysis of Fiber Distribution and Orientation in Ultra-High Performance Fibre Reinforced Concrete with High Fiber Dosages. Experimental techniques, 33, 50-55. 